\title{
El cronotopo del patio en textos de cuatro autores del Caribe colombiano
}

\author{
Lázaro Valdelamar Sarabia ${ }^{1}$ \\ Universidad de Cartagena
}

\section{Resumen}

En el presente ensayo se discute en qué medida la combinación de un espacio (el patio) y una temporalidad (infancia) constituyen una imagen literaria cronotópica -en términos de Bajtin-, permitiría hablar de trazas de una tradición en una parte de la literatura del Caribe colombiano. El ensayo da cuenta de cómo el cronotopo del patio fue elaborado, formal y semánticamente, por Héctor Rojas Herazo, en Respirando el Verano, y luego analiza la manera cómo fue retomado en textos de escritores regionales posteriores: En el traspatio del cielo, de Rómulo Bustos Aguirre, Pavana del Ángel, de Roberto Burgos Cantor y Glimpses, de Mario Jursich Durán.

Palabras clave: patio, infancia, tradición, identidad, literatura colombiana, caribe, cronotopo.

\section{Abstract}

In the present essay it is discussed to what extent the combination of a space (the yard) and a temporality (childhood) constitutes a chronotopic literary image -in terms of Bajtin-, would allow to speak of tradition sketches in a part of the Colombian Caribbean Literature. The essay reports on how chronotope of the patio was elaborated, formally and semantically, by Héctor Rojas Herazo in Breathing the Summer (Respirando el Verano), and then it analyzes the way how it was retaken in the subsequent regional writers' texts: En el traspatio del cielo(In the sky back yard) by Rómulo Bustos Aguirre, Pavana del Ángel, (Angel's Pavan) y Robert Burgos Cantor and Glimpses by Mario Jursich Durán.

Key words: back yard, childhood, tradition, identity, Colombian Literature, Caribbean, chronotope.

\footnotetext{
${ }^{1}$ Profesional en Lingüística y Literatura, Facultad de Ciencias Humanas, Universidad de Cartagena. Maestría en Estudios de la Cultura, con mención en Literatura Hispanoamericana, Universidad Andina Simón Bolívar, y candidato a Doctor en Estudios Culturales Latinoamericanos en la misma Universidad. Actualmente se desempeña como investigador del Instituto Internacional de Estudios del Caribe, IIECARIBE, de la Universidad de Cartagena, y como profesor del Programa de Lingüística y Literatura de la misma universidad.E-mail: eucaliptosverdes@yahoo.com.ar
} 


\section{Introducción}

Un texto, un autor, se constituyen como fundacionales a partir del momento en que son citados por textos y autores posteriores y a través de esas citas van obteniendo un reconocimiento que generalmente se expresa en atribuciones tales como "el primero" en "tratar ciertos temas, en abordar nuevas propuestas" (Verón, 1989).

Respirando el verano, de Héctor Rojas Herazo, es en el campo de la literatura del Caribe colombiano un texto fundacional, en la medida en que es una de las novelas que marcan el rompimiento con la narrativa decimonónica, introduciendo la modernidad literaria. Pero es un texto fundacional, sobre todo, porque en ella el autor utiliza y elabora literariamente elementos de claros matices regionales con tal efectividad artística que, a partir de allí, serán retomados por autores regionales posteriores a él.

Nuestra tesis es que un elemento particularmente identificatorio que permitiría hablar de trazas de una tradición literaria del Caribe colombiano es la persistencia del patio, básicamente como fue elaborado por Rojas Herazo en Respirando el verano, en textos de escritores regionales posteriores: Rómulo Bustos Aguirre, Roberto Burgos Cantor y Mario Jursich Durán.

Respirando el verano es una novela que surge en el momento de la reafirmación de la novela latinoamericana, momento en el cual los narradores de esta parte del continente ejercen un fuerte cambio en la orientación del regionalismo. Resumiendo, el cambio consistió en pasar de una mera descripción paisajística y hasta pintoresca del entorno como parámetro de una literatura latinoamericana, hacia el aprovechamiento de la realidad cultural y espacial latinoamericana como punto de partida para una experiencia literaria verdaderamente "iluminadora de la condición humana y [medio] de exploración de la realidad humana" (Brushwood, 1989: 172).

Para llegar al grado de pericia técnica y de manejo de la realidad latinoamericana, que de manera polémica se ejemplifica con los autores del llamado boom, se requirió la presencia de escritores que de modo crítico y creativo aclimataran las nuevas técnicas narrativas impuestas en Europa y Norteamérica, sin perder de vista sus propios imperativos culturales; tales escritores son llamados, según la conocida terminología de Rama, "transculturadores narrativos" (Rama, 1984: 218 y ss). Para describir el proceso de transculturación narrativa, Rama propuso la consideración de diferentes tipos de conflictos culturales a los cuales tuvo que en- 
frentarse el escritor latinoamericano de mediados de este siglo. Siguiendo a Rama, uno de esos conflictos era el que se presentaba entre las prestigiosas culturas nacionales y las regiones marginales que, en un mismo país, aparentemente, seguían las directrices impuestas desde las ciudades capitales, pero que mantenían un acervo cultural propio susceptible de ser aprovechado literariamente.

En Colombia, Héctor Rojas Herazo fue uno de esos escritores que se impuso como tarea la elaboración artística de los elementos de su cultura regional. Tales escritores se caracterizaron por ser, en su mayoría, de procedencia rural, y por tener la doble función de producir tanto discursos literarios como discursos críticos sobre el desarrollo de ese mismo campo. Estos últimos lo ejercían en columnas periodísticas y a través de entrevistas, adquiriendo el carácter de ratificaciones de las propuestas de sus autores acerca de lo que debía ser la literatura, sus temas y sus funciones en el conjunto de la cultura.

En el presente ensayo, aparte de la narrativa de Rojas Herazo (Respirando el verano, esencialmente, aunque a veces resultará necesario hacer referencias a otras obras del autor), acudiremos a algunas de sus notas periodísticas y conferencias para sustentar nuestra tesis.

\section{Identidad, patio e infancia en Rojas Herazo}

Ya desde los años previos a la publicación de las tres novelas que marcaron el inicio de la modernidad literaria ${ }^{2}$, en sus artículos publicados durante el período de Cartagena 1948-1959 en el periódico El Universal de esa ciudad, Rojas Herazo exponía como crucial para la formación de una literatura latinoamericana la necesidad de asimilar el propio espacio, tanto geográfico como cultural, a la literatura (García Usta, 1995). Así lo podemos apreciar en uno de sus artículos compilados en Señales y garabatos del habitante: "América, lo americano, no es un hallazgo. Es una búsqueda, un pálpito, una querencia. Por eso América -la posibilidad de lo americano como expresión- ha de traducirse en el orden poético" (Rojas Herazo, 1976b: 201). En el artículo titulado "Los mapas están vivos", identidad y espacio reaparecen aún más claramente vinculados en lo que podemos denominar el programa literario del escritor:

\footnotetext{
${ }^{2}$ Estas tres novelas son: La hojarasca (1955), de Gabriel García Márquez, La casa grande (1962), de Álvaro Cepeda Samudio y Respirando el verano (1962). Cfr. Williams (1981: 13).
} 


\begin{abstract}
Sí, están vivos lo mapas [...]. Todo mapa representa el esfuerzo de la especie humana por retratar su sitio en el cosmos [...]. La geografía es la hermana gemela de la poesía y de la historia [...]. Porque ella, la geografía es la madre de la leyenda, la generadora de las grandes empresas y los grandes asombros [...] que han transformado el carácter y la mentalidad del hombre. Por ella son posibles los conceptos de patria, de solar, de raza. (179)
\end{abstract}

De acuerdo con el diccionario, la palabra "solar" proviene del latín solarium, y ésta de solum, que significa suelo, cuna de una familia; y Rojas la asocia en su escritura a "patio", y a "pueblo", conservando la acepción de pertenencia que encierra la etimología de la palabra.

En nuestra cultura del Caribe colombiano es claro que la casa tiene como componente fundamental el patio, espacio abierto, pero a la vez protegido, sembrado de árboles generalmente frutales, y plantas, propicio para la infancia y sus juegos. El patio es también refugio para el calor, y por tanto, lugar de gran parte de las interacciones familiares. Por estas razones, para el hombre del Caribe un requisito esencial que debe llenar la vivienda es la presencia de un patio de la mayor extensión posible (y aún riñendo con la urbanización por apartamentos que siguen las ciudades).

Estas características son obviamente más acentuadas y visibles en las zonas rurales donde el espacio disponible es mayor y el patio puede rodear toda la casa, o puede estar ubicado en la parte posterior de la vivienda, como generalmente ocurre. En esas zonas este espacio puede llegar a ser de tales dimensiones que se habla de "patio", para referirse a la zona del mismo que está más cerca a la casa, y de "traspatio", para referirse a la que está más alejada. Creemos que lo dicho explica, por lo menos en parte, la alta carga simbólica con la que en nuestra cultura puede llegar a investirse el patio, así como explica el valor identificatorio que cumple su uso en la literatura, confirmando la observación de Bajtin (1989), según la cual:

Las tradiciones culturales y literarias (incluyendo las más antigua) no se conservan ni viven en la memoria individual subjetiva de un hombre aislado, ni en ninguna "mentalidad" colectiva, sino en las formas objetivas de la cultura misma (incluyendo las formas lingüísticas y verbales); están en ese sentido, entre lo colectivo y lo individual (y son por tanto sociales) de ahí pasan a las obras literarias. (399)

Por otra parte, sabemos que uno de los tópicos más recurrentes en la literatura es la infancia ensoñada como paraíso, estrechamente 
relacionada con el espacio donde transcurrió la misma (Bachelard, 1965). Así, encontramos que estos aspectos son objeto de una reflexión consciente por parte de Rojas Herazo en el texto titulado "Palabras sobre un oficio", en el cual el escritor pretende explicar la génesis de sus novelas, en relación directa con las experiencias de su vida. Allí declara: "Lo único que he deseado, en las diversas formas de comunicación que he ensayado hasta el momento, es narrar mi infancia." (1976b: 241). En ese artículo el autor sigue un orden expositivo que va de lo más externo (el país y el pueblo de Tolú), hasta lo más interno (el carácter originario del patio), y después de abordar aquéllos rasgos generales que de alguna manera pueden ser considerados válidos para cualquier infancia, explica el papel de su propia infancia en su novelística, definiéndola como especial, precisamente por las características del lugar donde se desarrolló: "La casa de nuestra abuela en Tolú -donde mi hermana Amalia y yo vivimos hasta los siete años y donde volvimos en las vacaciones de fin de curso, hasta que yo tuve los diez- quedaba a una cuadra del mar [...] Aquí reinaba la abuela [...]" (243).

Una vez descrita la casa, el reino de la abuela, el autor hace todavía una precisión más: ubica en el centro de su universo autobiográfico la infancia y el patio en una página que merece ser citada en su totalidad:

Mi hermana y yo éramos los dueños exclusivos del patio. Conocíamos sus escondrijos, la parte de las ramas en que los árboles daban sus frutos mejores, las palabras exorcizadoras cada vez que hollábamos las frondas tabúes, la eficacia para convertir los despojos oxidados -trozos de calderetas y pedazos de fleje, muñones de máquinas sínger, trozos de pilares o banquetas de un antiguo lecho salomónico- en seres vivos. Eran nuestros juguetes y compañeros. Amalia hacía verdaderos milagros con aquéllas hilachas de sábanas y toallas desparramadas al azar. De pronto, en qué sultán y con qué espléndido y abultado turbante, había sido transformado el polvoriento mazo de triturar maíz y en qué reina, con cetro y todo, aquélla escoba recubierta de trizados encajes y cuya frente de sandía o de totumo remataban unas trenzas de ortiga como corona de hierro. Lo demás era obra del patio enduendado: palacio el cobijo de palmas desprendidas; carroza la simple rueda, adosada con alambres y tiras a una cañabrava; cañones para defender una improvisada fortaleza, los troncos huecos de una palma de coco. Nuestra nobleza la conformaban las gallinas duquesas rodeadas de su prole y escoltadas por emplumados emires que llegaban de oriente; las iguanas y lagartos eran nuestros enemigos natura- 
les; los soldados encargados de defender el reino eran las hormigas rojas, las temibles guerreras, que alzaban sus bastiones entre las raíces de los tamarindos, contra el muro de piedra. Al otro lado de este muro vivía el hombre solitario que entendía el lenguaje de las moscas. (244 - 245).

Resulta interesante constatar cómo esta representación del universo vital autobiográfico sigue una disposición concéntrica (desde lo más externo y universal a lo más íntimo y particular) que se corresponde con la disposición del universo narrativo de Rojas Herazo, proporcionándonos así una especie de mapa semántico con el cual interpretar sus obras, pues en estas "patio, casa, pueblo y nación son los espacios concéntricos que albergan el mundo novelesco" (Gómez, 1995: 48).

De este modo, patio e infancia conforman una unidad indisoluble en la escritura de Héctor Rojas Herazo, una imagen cronotópica de acuerdo a la terminología de Bajtin, quien denomina cronotopo: "[Lo que en traducción literal significa tiempo-espacio] a la conexión esencial de relaciones temporales y espaciales asimilados artísticamente en literatura [...]. Entendemos el cronotopo como una categoría de la forma y el contenido en la literatura" (1989: 237). En lo que respecta a la función compositiva de este cronotopo, es muy pertinente el comentario de Álvaro Pineda Botero: "Para Rojas Herazo el patio es un recurso casi de naturaleza plástica, que adquiere el tono preciso para completar la descripción física o sicológica del personaje. Por eso en su obra el patio toma múltiples formas, desde lo meramente geográfico hasta lo más intimista y humanizante" (1990: 237).

Efectivamente, en Respirando el verano ya aparece el patio con todas esas funciones, en ella prácticamente no hay un personaje que en las más diversas situaciones no atraviese, mire o respire el patio. Por ejemplo, desde esta novela se define la vinculación de Celia, la figura central de la novelística del autor, a partir de sus relaciones con ese espacio, como se aprecia en el episodio del regreso de Jorge, tío de Anselmo, el niño protagonista: "La abuela se hizo sentir en el acto. Venía del patio, de su reino de hojas, de sus maticas de hierbabuena y toronjil, de su ámbito con olor a humo de leña, a pollitos recién nacidos, a burros y a jazmines. Cojeaba levemente desde su última caída en mil novecientos diez y siete. Traía la cabeza hundida entre los hombros, uno de los cuales, el derecho se alzaba levemente al caminar" (Rojas Herazo, 1962: 14). Como se puede apreciar, a partir de la relación con el espacio del patio se presenta a Celia como una matrona del pueblo, su estrecha vinculación con la naturaleza, a la par que se nos introduce en su biografía. 
Otro ejemplo se encuentra en el octavo capítulo cuando, en medio de la guerra civil, unos soldados acampan en la casa y la hija mayor de Celia, Julia, sostiene una discusión irónica con el teniente de la tropa que ha invadido la casa. Después de una fuerte tensión:

\begin{abstract}
Él pareció cansarse súbitamente, ladeó el rostro y miró las rojas fogatas en el patio y a los hombres sentados, en camisa, aspirando ansiosamente el olor de la carne asada. Recordó los caminos y las balas aullando en los pretiles del último pueblo. Se oyó así mismo gritar mientras veía a un joven de mostachos azulosos, con su boca de niño abierta en actitud de responder, llevándose las manos al pecho, arrodillarse como quien va a rezar entre el humo, y luego recostarse, ensangrentado y suspirante, en una escalera de piedra. Volvió sus ojos a Julia mientras escuchaba los caballos resoplando en el patio. Sintió hambre y hastío [...]. (66).
\end{abstract}

Aquí el patio sirve como punto de fuga hacia el recuerdo del oficial, y a la vez, el salto de su pensamiento al pueblo evocado dinamizan la narración, y todo contribuye a humanizar la figura del teniente, quien hasta el momento aparecía como un ser completamente hostil. La intensidad plástica que adquiere el patio es tal que Rojas llega a presentarlo como un ser con vida propia:

\begin{abstract}
Abrieron con precaución la puerta falsa y salieron. El patio, agujereado por secretos reflejos, murmuraba en silencio. Y no era simplemente el brillo de la luna, la fuerza y el secreto de los árboles [...] era más bien aquélla substancia, lúcida, perfumada, que tenía la atmósfera. Como si el toronjil y los jazmines se hubieran apoderado de la noche y, aromando la propia luz, comunicaran al tiempo, al aire que fruncía las hojas, un ademán de dolorosa intensidad que recordaba a la muerte. Anselmo miró los tiestos de agua donde bebían las gallinas y preguntó: - ¿No te da miedo? [...]. (192).
\end{abstract}

Además, es necesario anotar que esa exploración plástica le permite a Rojas ejercer, en esta primera novela, su reconocida habilidad en el manejo de la descripción y el vigoroso lirismo que hace de la suya una prosa de fulgurante, de fuertes trazos, de ricos matices; sin duda una de las prosas más destacadas en lo que va de la historia de la literatura colombiana.

Desde el punto de vista del contenido, encontramos que si bien la casa es un motivo recurrente ${ }^{3}$, el centro de la misma es la imagen cronotópica

\footnotetext{
${ }^{3}$ Como ocurre en varias obras de la modernidad literaria colombiana.
} 
del patio, "es el patio que implica el contacto con la tierra, con el cosmos, con los aromas, con los olores, es el paraíso terrestre de lo material y la sensualidad [...] en la posibilidad de abarcar el universo desde la intimidad" (Gómez, 1995: 47). En ese sentido, resulta significativo el hecho de que al inicio de Respirando el verano, para representar a Anselmo -el niño protagonista-, Rojas Herazo utilice un procedimiento análogo que comentamos con respecto al artículo "Palabras sobre un oficio", esto es, confiriéndose identidad, realidad, a través de su pertenencia a un espacio específico, que no podía ser otro que el del patio, invistiendo a la vez al personaje de un fuerte componente autobiográfico:

\begin{abstract}
Anselmo amarró el corcelito de palo en uno de los balaústres de la ventana y, sentándose en el pequeño mecedor, empezó a desprenderse de las medias y los cordones de sus zapatos, las bolitas de cadillo que se le habían adherido en su desenfrenado galope por el patio [...] y el recuerdo del patio, de su patio, calcinado y brillante como todos los seres y objetos de aquel tenso verano, lo sentía en las ropas, en la palpitación de sus pies, en la cabeza de sienes hirvientes. La mañana había pasado rápidamente [...]. (11).
\end{abstract}

Centro del universo vital y autobiográfico, el patio aparece como lugar excepcional, único, en tanto cumple la función de conferidor de identidad, de realidad, en virtud de lo cual resulta coherente considerarlo como punto cósmico originario en la visión del mundo de Rojas Herazo ${ }^{4}$. Esta característica originaria del cronotopo, que ya vimos definiendo la identidad de Anselmo, se hace extensiva a todos los personajes de esa saga familiar que es Respirando el verano. Así, vemos en el capítulo XIX, que Horacio, el tío mayor de Anselmo, en franca agonía, recapitula toda su existencia, descubriendo que los momentos claves de la misma (el nacimiento, la infancia, el amor, la guerra y ahora la muerte) están ligados al patio: "Ahora, hundido en su silencio, embestía el recuerdo contra sí mismo. Aquí, en este mismo patio, había brotado y crecido como una planta rubia [...] su verdadera vida, como la de sus padres y sus hermanos había transcurrido en este patio [...]. De este patio salió la vida [...]” (151).

Una situación similar vive Valerio, el otro tío, quien, al sentirse asediado por el misterio de la existencia, recurre a su relación con el patio para tomar fondo en sí mismo: "Que es esto, esto [Sic], se decía -Valerio recorría con lenta y ardorosa mirada el amado patio, cada una de sus re-

\footnotetext{
4 "Subsisten lugares privilegiados, cualitativamente diferentes de los otros [que] conservan, incluso para el hombre más declaradamente no religioso, una cualidad excepcional, 'única'; son los 'lugares santos' de su universo privado": (Eliade, 1992: 28).
} 
conditeces [...] Gravándolas con firmeza en su corazón. ¿Qué es esto? [...] y se vio a sí mismo confuso y lleno de las preguntas bajo los árboles [...]. Valerio sintió el amargo esplendor de su tarea: Seguir viviendo" (203).

Este carácter originario del patio ha sido también señalado por Ben Séller (1994), para quien, empero, el centro de la novela lo ocupa Celia. Sin embargo, desde nuestro punto de vista, el acto narrativo proviene de un Anselmo adulto que recuerda, en virtud de lo cual, el objetivo del acto narrativo responde a la actitud imaginaria del retorno al origen (Cfr. Durand, 1981). Y si bien Celia, por su condición de matriarca, condensa gran parte del simbolismo nocturno correspondiente a dicha actitud, para nosotros es claro que el trayecto imaginario de la conciencia narrativa termina justo un poco más allá ${ }^{5}$, en la Ginitrix por excelencia: la Tierra Madre, con la cual se está en pleno contacto en el patio (Gómez, 1995). El personaje mismo de Celia se inscribe en este movimiento imaginario del retorno:

Porque él [ el esposo, monologa Celia ] se ha ido, mis hijos se irán y yo también he de irme [...] pero aquí, en esta tierra que piso, la que ahora golpeo duramente con mi pie derecho, quedaremos nosotros, rondando, llorando y exigiendo [...]. Algún día, después de muerta (esto lo sé también ) rondaré por estos almendros y oirán mi voz en este patio. Porque, Dios mío, esto no puede morir, esto no puede morir! [...]. Tampoco morirán mis hijos. Mis hijos seguirán aquí. Ahora él (Horacio) se está acabando [...]. Pero yo sé lo que pasa. No es que vayan a morir. Es que se está despojando para poder esconderse. (Rojas Herazo, 1962: 164-165).

Esta actitud de Anselmo, en cuyo recuerdo perdura Celia y el cual se interfecta a cada paso con la conciencia del autor, traduce así una visión del mundo en la cual, ante el paso inclemente del tiempo y la ruina que provoca, ante la precariedad y destrucción infligida por su transcurrir a los seres y objetos, se esfuerza en contrarrestarlo atesorando en la memoria lo vivido. Razón por la cual en la escritura de Rojas Herazo nos encontramos con un puro pasado, pasado al fin, pero que no se corrompe, sino que perdura, en cuanto está inmóvil en la memoria. Tiempo detenido donde las imágenes evocadas se superponen, no se suceden. De tal modo que allí "el espacio lo es todo" (Gómez, 1995). Esta tendencia alcanza su punto máximo en su última novela Celia se pudre (1982). Según análisis de Troncoso

\footnotetext{
${ }^{5}$ Esta idea acerca de que Anselmo recuerda, mientras Celia perdura en ese recuerdo, es también sostenida por Brushwood (1994: 151).
} 
(1989), allí Anselmo es ahora un burócrata desarraigado y anónimo que trata de encontrarse a sí mismo refugiándose en la memoria:

[...] el yo-narrador, al mismo tiemo héroe-niño, debe ir a comprar las calillitas de Ambalema para la abuela, quien le muestra el confesionario y el barco donde se las venderán. El adulto-niño va hacia el interior del barco por los pasillos del ministerio $\mathrm{y}$ todo vuelve a empezar en esquemas de tiempo circular [...]. Volver al barco, volver a los juegos de la infancia [...]. (191)6.

De ahí el estilo de Rojas Herazo. Un estilo rico en metáforas, sinestesias y exploraciones escatológicas que se compagina con las aspiraciones fusivas, analógicas, propias del régimen nocturno de la imaginación, con el cual podemos relacionar su visión de mundo (Durand, 1981: 257 ss). Una visión de mundo y un estilo que tienden a acercar y asimilar sensaciones, animales, seres humanos y objetos entre sí concebidos como un todo entretejido y vivo. Este tipo de relación con los objetos y el entorno explica las razones por las cuales el cronotopo, en cuanto a tiempo-espacio lúdico, fascina a quienes se acercan al texto autorreflexivo "Palabras sobre un oficio" de Rojas que citamos arriba.

Para la cultura industrial a la cual pertenecemos, el juguete no es un objeto resultante de las acciones exploratorias del niño sobre el entorno, de algún modo brotado de la subjetividad, sino generalmente un puro objeto fabricado cuidadosamente por-los-adultos-para-los- niños. Lleva incorporados en su diseño y modo de producción las instrucciones de manipulación y fines que otros han inscrito en él, y con ello, modelos establecidos de realidad, limitando así la libertad por medio de las cuales el juego permite una definición mucho más flexible, y por lo tanto, más libre del yo en confrontación con el mundo a partir de la propia experiencia. De allí que no sea extraña la fascinación que ejerce el cronotopo en tanto su connotación lúdica. La inteligencia es seducida por la naturalidad con la cual, en el recuento de Rojas Herazo, esos restos de objetos (calderetas, pedazos de flejes, muñones de máquinas), gracias al movimiento libre de la imaginación son transformados "en seres vivos". Son rescatados de su condición puramente objetual y se convierten "en juguetes y compañeros". Nos seduce la maleabilidad según la cual todo, gallinas, lagartos, hormigas son integrados a los requerimientos creativos del mundo subjetivo. Podemos decir que en ese texto de Rojas, como en el pensamiento libre, espontáneo de la infancia, el juguete es el juego mismo. Es la puesta en marcha de la capacidad creativa del niño en un espacio que le permite asimilar el mundo

\footnotetext{
${ }^{6}$ Sobre la importancia dada al espacio para neutralizar el tiempo en esta novela ver también: Pineda Botero (1990: 40-44).
} 
sin la rigidez y monotonía del mundo externo, hostil que se inicia justo al otro lado del muro de piedra donde habita "el hombre solitario que entiende el lenguaje de las moscas"7.

\title{
2. Los visitantes del patio
}

\begin{abstract}
"Aceptar una influencia, sobre todo si es una gran influencia es aceptar la tradición. Solo quien ha sidoinfluido muy a fondo (por uno o muchos escritores parientes) puede ser un creador, los otros, los que se dejan influir a medias, serán los escritores mediocres. El verdadero escritor no batalla con sus elecciones esenciales".
\end{abstract}

Rojas Herazo, Señales y garabatos del habitante

Hemos visto cómo la aparición del cronotopo del patio en la escritura de Héctor Rojas Herazo se relaciona con un proyecto literario para el cual era decisiva la definición de identidad cultural ${ }^{8}$, cuya consolidación se consideraba, en gran medida, dependiente de la conformación de una literatura con rasgos culturales definidos a partir de lo cual sería posible alcanzar validez universal.

En lo que sigue, pretendemos mostrar que, por lo menos en lo concerniente a la literatura del Caribe colombiano, la función identificatoria con la cual la elaboración artística del cronotopo del patio aparece investida en Respirando el verano y en los textos de Señales y garabatos del habitante ha tenido repercusiones en la literatura posterior, hasta el punto de que, con base en las recurrencias del cronotopo en los autores de diferentes generaciones, se puede hablar de una continuidad en la historia literaria regional, esto es, de una tradición. Para confirmarlo, intentaremos constatar la presencia del cronotopo en textos de otros tres autores de la región: En el traspatio del cielo, de Rómulo Bustos Aguirre (Santa Catalina de Alejandría, Bolívar, 1954), Pavana del ángel, de Roberto Burgos Cantor (Cartagena, Bolívar, 1948) y Glimpses, de Mario Jursich Durán (Valledupar, Cesar, 1964).

\subsection{El cronotopo en el plano vertical}

Veíamos que en Rojas Herazo la imagen cronotópica del patio se encuentra vinculada a las ensoñaciones nocturnas de la intimidad y

\footnotetext{
${ }^{7}$ Para lo expuesto sobre el juguete, Cfr. Jaulin (1987).

${ }^{8}$ Esta era una preocupación central de la literatura latinoamericana del período. $\mathrm{Al}$ respecto, confrontar Rama, (1982: 48 ss).
} 
el reposo. Tales ensoñaciones reaparecen en el libro de poemas En el traspatio del cielo (Bustos Aguirre, 1993) ocupando el centro del quehacer poético, y también, como en Rojas, vinculadas a referencias autobiográficas.

Las presencias que ocupan el centro íntimo del refugio En el traspatio del cielo son la de los hermanos, los juegos infantiles, los árboles frutales; pero sobre todo se destaca la presencia de la madre. Son éstas presencias que hacen del traspatio recordado el paraíso ensoñado, como lo revelan los títulos de los poemas: "Crónica de la madre", "Crónica de los hermanos", "Crónica de la hermana mayor", "Crónica del patio", "Crónica de la madre del ángel”, "Cometa”, "Poema de las pertenencias", "Poema a la hermana menor" y "Balada de la casa", amén de la abundancia de dedicatorias a seres queridos.

Estas ensoñaciones las encontramos especialmente expresadas en el texto a través del simbolismo de los colores. El poema que abre el libro, "Días lentos", es rico en este simbolismo. Además de recurrir al verde y al amarillo, colores de la intimidad, enfatiza su contenido acudiendo a la lentitud y a la redondez, para evocar las condiciones de un universo conformado por los vínculos, el reposo y la calidez que permanece en la memoria, "a la orilla del tiempo":

\author{
Días lentos \\ y verdes y amarillos como grandes camaleones \\ a la orilla del tiempo \\ Y a la vez azules Yo los quisiera eternos \\ Sobre un cielo redondo dulcemente curvado \\ por la mano de un niño \\ Yo los quisiera azules y redondos \\ como la vieja taza de peltre en cuyo fondo \\ volaba hechizada una brisa de pájaros. (1993: 11)
}

No a otra belleza se refiere el epígrafe tomado de Elíseo Diego "[...] La belleza será sólo el fragmento/ de algo roto que tuvo en cada sitio su/ áureo centro y hoy es fuga y nostalgia/ y extrañeza". La voz poética positiviza el pasado por el valor de la inocencia de la infancia, instaurando de esa manera una polémica con el presente desde el que se habla. Pero la polémica con el presente es llevada un poco más allá en el libro, hasta hacer de la inocencia perdida la experiencia previa de una entre-vista posibilidad de acceso a lo absoluto. Acceso que la voz poética proyecta en términos de una búsqueda de la $p u-$ reza. Búsqueda que se hace manifiesta desde el otro epígrafe: "sigo tirándole piedrecillas al cielo/ buscando un lugar donde posar sin mucha/ fatiga el pie", de Raúl Gómez Jattin. 
De esta manera el texto, en virtud de su condición poética, funciona semánticamente con base a un amalgamamiento de los regímenes imaginarios, diurno y nocturno, de la imaginación ${ }^{9}$. En consecuencia, En el traspatio del cielo se nos presenta como un texto en el cual las ensoñaciones de la intimidad y el refugio, condensadas en la imagen cronotópica del patio, son transpuestas, como por un efecto de la distancia temporal, al plano de las jerarquías axiológicas del hablante en tanto se impone la pureza como absoluto. Estos es, al plano de la verticalidad diurna. Una aspiración a la pureza concretizada en la vocación de angelismo que recorre el libro y cuya metáfora más recurrente en el mismo es la del vuelo ${ }^{10}$.

El cronotopo funciona entonces como bisagra en la oscilación constante de un régimen a otro, especialmente por la individualización de uno de sus componentes plásticos: el árbol. El patio es centro en cuanto imagen nocturna, familiar, originaria; y es umbral, en cuanto tiempo-espacio propicio a la irrupción de lo no cotidiano, del milagro, de la trascendencia. Pues es la vivencia del milagro y la inocencia en el traspatio de la infancia la que enciende en el hablante lírico (adulto) el deseo de elevación. El poema "Árbol camajorú", del que citaremos la primera parte, nos lo impone así, al ubicar en él el axis mundi ${ }^{11}$ :
I.
En lo hondo del traspatio
Más allá del mango, de los durmientes ciruelos
está el árbol solo, el solitario camajorú
rodeado de sed, hechizado en el tajo de luz
en que una vez se le abrió el cielo
Todos lo miramos de lejos
Pero sus ramas ya no podemos verlas. Sus ramas

\footnotetext{
${ }^{9}$ En "Días lentos" esta simultaneidad de regímenes ya está marcada, pues, además del verde y el amarillo, está presente el color azul, color asociado a la divinidad, a lo absoluto (Durand, 1981: 139). Con respecto a las implicaciones diurnas del color amarillo, Durand mismo pone de manifiesto esa ambigüedad, atribuyéndolo al carácter multisemántico de lo simbólico.

10 "El arquetipo profundo de la ensoñación del vuelo [...] [es] el ángel, y toda elevación es isomorfa de una purificación por ser esencialmente angélica" (Durand, 1981: 125). Esta vocación de angelismo se hace manifiesta en los poemarios anteriores del autor El oscuro sello de Dios (1985) y Lunación del amor (1990), especialmente en éste último.

${ }^{11}$ Otro poema donde la verticalidad y el angelismo aparecen nítidamente es "Crónica de los nueve cielos", en el mismo libro. Un análisis más amplio de este último lo encontramos en Nieves Oviedo (1994: 211-214).
} 
Son invisibles

Sus ramas volaron a lo alto. Sus ramas quedaron

prendidas en lo alto

Y son ahora el techo del mundo. (12)

Sus ramas volaron alto. Son ahora el techo del mundo. Se evidencia el investimiento axiológico de que es objeto el cronotopo y la irrupción del milagro en él: el árbol está hechizado en el tajo de luz en que una vez se le abrió el cielo, "porque ¿no es la pureza en quintaesencia rayo, relámpago, y deslumbramiento espontáneo?" (Durand, 1981: 162). La metáfora es reformulada con todas sus resonancias afectivas en "Crónica del mediodía", acudiendo al simbolismo del color y la mención directa de la madre, amalgamadas con los valores diurnos del vuelo (el pájaro) y la pureza (la luz):

La luz se empoza en los techos de zinc

Un pájaro canta

Y su voz es un hilo tendido entre el pico

y el color amarillo que ha hecho nido

en lo alto

Sería dichosa la madre

si en él pudiera tender la ropa recién lavada [...]. (21)

"Crónica del patio" insiste en el cronotopo como tiempo-espacio propicio al misterio: "[...] el patio es un fantasma silencioso/ la luna se ha derramado gota a gota", y todos los objetos son impregnados de esa condición especial "[...] como si entre la luz y la sombra/ volvieran las cosas -extrañas- a su condición/ más verdadera”.

El poema que le da título al libro conjuga todos los elementos que hemos indicado hasta ahora. De manera ejemplar, nos muestra el traspatio de la infancia transpuesto de la dimensión horizontal, a la que pertenece como referente real autobiográfico, a la vertical. En él las alusiones al absoluto (fruto invisible, Deseo Resplandeciente de lo Alto, círculo) aparecen explícitamente relacionados con la pureza, debido a la asimilación del cielo con al agua lustral, elemento purificador por excelencia ${ }^{13}$, insistiendo, además, en el árbol como la escala celeste que comunica el arriba sagrado con el abajo profano, de tal forma que el traspatio es ahora la fuente de la pureza absoluta:

Sobre nuestras cabezas -flotante-

la casa del agua

Altos bosques acechantes de lluvia

Árboles con raíces en otra parte

en cuyas frondas mora el fruto invisible 
que la gente al pasar mira y señala con el dedo y nombra diciendo Deseo Resplandeciente de lo alto

Allá sobre nuestras cabezas -flotante-

el río que una mano oculta estremece y deshoja como un árbol

y así en mitad de sus ramas queda suspendida

la infatigable barca que lo surca

El viejo roble que enflora y desangra

En el traspatio del cielo

Cuyo extraño reflejo en el agua es un círculo. (28).

Como toda epifanía que se precie de serlo, la trascendencia sólo se presenta a través de una señal, en este caso, la del círculo. El elemento lúdico del cronotopo entra a funcionar en la misma dinámica. En el traspatio del cielo el juego de la infancia está ahora cargado de implicaciones existenciales. El texto maneja a un tiempo la extrañeza por la condición de pérdida y la búsqueda de la pureza. En los poemas donde se presenta la inocencia como condición de la infancia propiciadora de la ejecución de todas las posibilidades, se evidencia también la confianza en una capacidad mágica de la palabra tanto para crear el juego como para generar el recuerdo e introducir en el presente, a través del poema, la posibilidad de acceder a lo absoluto deseado. Por eso en "Matarratón", con el solo deseo y la intervención del conjuro, el hablante logra hacerse de un caballo de manera mágica, completamente ajustada a su ensoñación.

En realidad, "Matarratón" inicia una serie de tres poemas cuyo referente es la costumbre infantil de cortar ramas de dicho árbol y utilizarlas como corcel de palo, incluso haciendo muescas y grabados sobre las mismas para adornarlas. El segundo poema de la serie, "Vuelo y construcción del caballo de palo", exige que sea elaborado del matarratón "más puro", precisamente "de la vara más alta/ para que ya esté acostumbrado al cielo". En "Ajedrez", el hablante inicia indagando por su extrañeza ante la condición perdida: "El caballo su hijares de madera y viento/ aún levanta su delgado vuelo?”, para luego contrastar, desencantado (no en vano este poema está dedicado a Giovanni Quessep ${ }^{12}$ ), la pérdida de su eficacia para imaginar. Sólo encuentra despojos, "los guerreros del sueño/ sus verdes armaduras caídas/ como fantasmas sobre el vasto patio", y termina dramáticamente preguntando "dónde, madre, las torres desaladas de tu reino?" En "Peregrina", "el juego preferido", los ángeles celestes empujan "un guijarro imaginario", deján-

${ }^{12}$ El desencanto ante la posible ineficacia del ensueño poético es uno de los rasgos definidores de la poética de Giovanni Quessep. Cfr. (1982: 14 -16). 
dolo caer a la tierra: "Cierta vez imaginaron que la mano de un niño/ lo lanzaba de vuelta y pudieron recogerlo/ Así quedó trazada la ruta de los peregrinos/ del cielo" (32).

Pero los únicos guijarros con los cuales cuenta ahora el hablante son las palabras, los versos del poema "Guijarros imaginarios", ante la irreparabilidad de la pérdida de la infancia cronotópica, la misma que, sin embargo, es a la vez sentida como imagen previa de un hipotético paraíso. Por todo ello, el libro concluye con la imagen ambigua del arquero (ahora armado con una honda) apuntando a un absoluto que quizá sólo existe en el poema:

La palabra golpeando un color imaginario

Es tan alto el techo del mundo con su incansable azul siempre alejándose

Hay una ventana o un abismo en cuyo borde se escuchan trompetas ¿o son pájaros invisibles picoteando inútilmente el fruto dorado, el almohadón de oro donde Dios recuesta su fatiga?

La palabra rompiéndose en la falsa flor del eco Cayendo pedregoza

0 dormida en el aire. 0 lanzada en el fragor de una onda

largamente tensada en el más indigente y fervoroso de los sueños (52)

Ascender al traspatio del cielo implica entonces un descenso por entre los cálidos ramajes de la memoria. Para desempolvar las alas. 0 tal vez, para hacerlas brotar.

\subsection{Pavana del ángel: el cronotopo y el erotismo}

Como Respirando el verano y En el traspatio del cielo, Pavana del ángel nos presenta a un sujeto sumergido en la delectación de una infancia sentida intensamente como paraíso dejado en el pasado, pero recuperable a través de la escritura, y como en esas obras, se trata de una infancia transcurrida en un patio. Un tiempo-espacio que le permite al protagonista estrenar los sentidos en medio de un paraíso de plantas y árboles nativos que remiten a la geografía del Caribe colombiano. Allí se entra en contacto con el entorno, los animales, flores y pozuelos de aguas lluvias, sin mayores peligros: "El patio es grande y oscurecido al fondo por las ramas entrecruzadas de las ceibas, las majaguas, los cocoteros, los ciruelos gamosos, la flor de playa, los tamarindos y las acacias con la explosión de manojos colorados". Allí la luz de la mañana "despierta la algarabía incesante de 
las guacamayas y los turpiales que se arremolinan [...] y alborotan las carreras del viento de las iguanas y las lagartijas [...]. Al patio lo barren temprano con las escobas de palma y los rastrillos que dejan un surco entre los hoyos de los cangrejos y los montículos de los hormigueros (Burgos Cantor, 1995: 29).

En consonancia con la naturaleza paradisíaca, intimista, del espacio evocado, el niño de Pavana del ángel ha contado con la presencia benefactora de su aya, Elsa Mordecay:

Ella es la muchacha que se encarga de que él duerma temprano, que se ponga ropa limpia, que se coma los alimentos, que tome el jarabe contra la tos ferina, la emulsión del hombre del pescado para la fortaleza y el aceite de ricino que mata las lombrices. Le canta historias sin fin que alejan el miedo y llaman el sueño y lo baña con agua tibia en que ha cocinado ramas de hinojo y hojas de matarratón que evitan los golondrinos y alivia los brotes de sarpullido. (9)

Sin embargo, el cronotopo se inscribe aquí dentro de lo que la visión del mundo de la novela postula como máxima aspiración de la existencia humana: el erotismo. De hecho, la narración se inicia con la irrupción inesperada, epifánica, del amor en la vida del protagonista: "Lo que ocurrió fue casual". Y lo acontecido se narra con todos los rasgos de una aparición religiosa: en la lluviosa mañana el niño persigue una iguana hasta la pared que comunica con el patio vecino y...

Después del sombrío, en el claro entre los frutales y la casa vio a la niña [Hortensia de las Mercedes], descalza, con un camisón largo y trasparente y los cabellos aún dormidos sobre los hombros [...]. Atrapado por el encanto de la visión, unido en un estado nuevo de plácida contemplación, incrédulo y tenso porque en un instante podía desaparecer [...]. Cada día, desde esta vez, se salió de la casa temprano para irse al final del patio y mirar y mirar, con fortuna diversa [...]. (10).

Pero es a Elsa a quien debe su iniciación en el erotismo; son de ellas, se dice, "las primeras tetas que conocí sin deber de alimentación" (116). Una escena que resume con precisión esta semantización amorosa del cronotopo es precisamente aquella en la cual a media noche el niño, antes de regresar a su habitación, sale, por el corredor al patio y "se encanta. Es el patio que él conoce" (111). Recostada sobre la pared del fondo, junto al maquinista, ve cómo "Su aya, su compinche, Elsa Mordecay, levita en la noche lechosa del amor para que él, su niño consentido, vea que en cada ser está enjaulado un 
ángel" (114).El elemento lúdico que nos es familiar en el cronotopo encuentra su participación en el texto:

\section{JUGARON A ESCONDERSE}

Ella se pone de cara a la pared y con la mano se cubre los ojos [...] [a él] le gusta ocultarse en el patio. Detrás de algún árbol [...] la carbonera es su escondrijo favorito [...]. Se queda quieto [...]. No cae en la trampa de responder cuando ella lo llama y le hace preguntas para tentarlo. Espera y ella entra, despacio [...]. El estira los brazos y las manos quedan junto a los hombros de ella [...]. La toca, los dedos le anuncian que la toca, y por ellos le corre el torrente de una sensación [...] La cabellera es dócil, está seca y huele a flores [...]. Arrima su rostro al de ella que no dice nada. Paralizada. Pone sus labios cerrados en la boca de ella [...] está empinado [...]. Se aparta y huye corriendo. La luz lo deja ciego [...]. (43 44)

Precisamente son éstas las imágenes que danzan en la memoria del protagonista, justo antes de morir, enfrentándose a duelo con su suegro, puesto que, después de haberse casado con Hortensia de las Mercedes, cede a las presiones de la suegra, descargando su resentimiento contra la primera, perdiendo el norte de su existencia; exiliándose a sí mismo del paraíso:

Todo lo otro parece asolado por las purificaciones de la realidad. Como si ella hubiera impuesto un florecimiento en medio del cenegal removido de un dolor al que no le halló su causa y el peso de sentir que aun el amor sucumbía al mal entendido sin final por el que desbarrancaban los puentes de silencio compartidos con Hortensia de las Mercedes. La muchacha se había bajado de los zancos y él se quedó hablando solo a las alturas [...]. (272).

Interesa también señalar cómo, mediante el uso de la intertextualidad, el autor de Pavana del ángel hace manifiesto un deseo de ser reconocido como un autor de la literatura regional del Caribe. Ello, aparte de la explícitamente asumida relación entre su prosa y la de Gabriel García Márquez. Lo que nos interesa destacar como respaldo para nuestra tesis es que esa intención se pone de relieve en el caso de esta novela con el recurso al cronotopo del patio, reforzada por los guiños y citas de las obras de los escritores analizados en este ensayo. Por ejemplo, en la página 135 encontramos una alusión a En noviembre llega el arzobispo, de Héctor Rojas Herazo: "El Arzobispo. [avanza] arrastrando los bordes carcomidos por los escalones, las losas del piso, el frú-frú que gasta, diría un poeta del reino, de sus ropajes de espesa jerarquía". 
Cualquier ambigüedad acerca de la identidad del "poeta del reino" se resuelve, para un lector cómplice, por el uso de la onomatopeya frúfrú, fórmula idiolectal recurrente de Rojas Herazo.

La intertextualidad con la obra de Bustos Aguirre en la novela es también rastreable. En la siguiente cita vemos que en Pavana del ángel Burgos Cantor aprovecha la mención del municipio donde el primero nació para efectuar el guiño de complicidad con su lector, quien debe percatarse de la referencia tanto a la pintura geométrica y laberíntica del autor de En el traspatio del cielo, como al primer poemario publicado del mismo titulado El oscuro sello de Dios (1985): "El diseño urbano copiaba fragmentos de unos legajos abandonados en la ermita de Santa Catalina de Alejandría y que parecían corresponder al proyecto de un complejo de laberintos cuyo tránsito sin desespero purificaría y llevaría al oscuro sello de Dios" (Burgos Cantor,1995: 198).

Un guiño intertextual, esta vez con En el traspatio del cielo -todavía mucho más pertinente al análisis que hemos hecho aquí de Pavana del ángel, en la medida en que el traspatio aparece vinculado al absoluto, al cielo-, que postula la novela (el erotismo), lo encontramos en la página 105, cuando el maquinista del tren expresa que Elsa le ha dado la oportunidad de acceder a dicho absoluto: “ [...] tú sabes, sí, sí, eso, sólo eso, tú entiendes mi amor, mi amor: que iré hasta el final del traspatio donde me esperas sin espera, llego sin demora ahí, al final de los patios y te encuentro a tí. ahí, ahí, contra la última paredilla del último patio del universo donde después queda el precipicio del mundo [...].

Burgos Cantor permite ver cómo se integran elementos de la tradición con las obsesiones particulares de un autor. En Pavana del ángel encontramos resonancias (de hecho aquí la confluencia la establecemos desde nuestra conciencia de lectores) del texto de Rojas "Palabras sobre un oficio", pero en lugar de hormigas contra el muro se encuentran los comejenes a lo cual se asocia la imagen del tren, una imagen obsesiva en el recuerdo de Burgos, que él mismo considera como uno de los núcleos de su narrativa ${ }^{13}$ : "La paredilla que cierra el patio al final es de media altura y en una esquina espilan los troncos de las ramas desgajados. Están cubiertas de un repello sin cubrir y la superficie es irregular, llenas de túneles de comején. Por aquí pasan los pitazos del tren" (29).

En conclusión, no se puede obviar que el cronotopo aparece en Pavana del ángel en razón de las experiencias del autor, así como tampoco

${ }^{13}$ Cfr. el texto autobiográfico de Burgos Cantor publicado en el Dominical de El Universal de Cartagena el 9 de junio de 1996, No 537, pág. 3. 
se puede pasar por alto el hecho de que esa experiencia personal es enriquecida, y a la vez leída como parte de un mismo corpus literario que parte de un lector que ha estado en contacto con las dos obras de los otros autores ${ }^{14}$ que preceden a la escritura misma de la novela y que hemos analizado aquí, precisamente por la recurrencia del cronotopo. Así mismo, el valor identificatorio (en el sentido de pertenencia a una cultura) del cronotopo del patio encuadra perfectamente en el universo narrativo de un autor cuya poética, acudiendo al recurso de la memoria para ensoñar la Cartagena de mediados del siglo XX (la relativamente armónica Cartagena de su infancia), en pugna con los jalones de nuestra siempre caótica modernidad, representada entonces por la apertura a la industria turística y al acelerado crecimiento urbano, pretende "[...] recuperar un espacio y fundar un nuevo imaginario capaz de rescatar las esencias de un ámbito, que define valores colectivos y sustenta un sentido de pertenencia a la especie humana, a Colombia y a su región costeña" (Figueroa, 1985).

\subsection{Un glimpse a Glipmses}

"Había un patio a la orilla del mar, un tamarindo de amargas hojas y una historia olvidada de hombre. Con el verano, la reja se despintaba y sobre las tumbas el viento cernía un polvo amarillo. Allí tiraron la fruta. Allí se pudrió y allí mismo vago remedo de muerte la fruta se embozó en la oscura tierra del silencio".

Glimpses

En el caso de Glimpses (Jursich, 1990), a diferencia de lo que vimos en las obras de los autores anteriores, no hay en el texto una referencia autobiográfica directa a la imagen cronotópica del patio. En realidad, debido a la estética de la parquedad, y por lo mismo marcadamente simbólica, con la cual el poemario desarrolla su temática, el cronotopo parece sujeto a una estilización más, por decirlo así, estrictamente literaria, y por lo tanto, sin referente geográfico-cultural específico aparente. Sin embargo, la aparición del árbol como referente y como símbolo nos da bases para relacionar a Jursich Durán con los autores regionales aquí tratados, permitiendo una localización geográfica y cultural del lugar de producción del texto en la costa Caribe del país. Ya en el caso de Bustos Aguirre vimos el papel central del matarratón y del camajorú; en Pavana del ángel, la función plástica la cumple con creces el árbol de mango, mientras que en Respirando el verano dicha

\footnotetext{
${ }^{14}$ Pineda Botero también alude a la continuidad que la presencia del patio en $E l$ patio de los vientos perdidos, de Burgos Cantor, tiene con relación a Respirando el verano (1990:38).
} 
función la cumple el guayabo junto al tamarindo, el cerezo y el mango. Del pequeño bosque que es el patio, Jursich prefirió el Tamarindo y "sus amargas hojas", para hablar metafóricamente del Hombre y su estadía en La Tierra.

De un modo mucho menos sutil, el epígrafe del texto nos informa que Jursich Durán conocía, al momento de escribir el libro, la obra de Héctor Rojas Herazo, a partir de lo cual podemos inferir que si echa mano de dicha imagen, lo hace recurriendo a un elemento geográfico-cultural de alguna manera ya integrado al discurso literario. En seguida veremos cómo funciona el cronotopo dentro de la visión poética expresada en este texto de Jursich.

En Glimpses la visión poética de Jursich Durán es netamente metafísica, y como tal, el discurso poético se mueve entre los extremos absolutos de la conciencia humana: entre el mar y el desierto, entre la nada y el infinito, entre la vida y la muerte. La vida del hombre es, en medio de estas totalidades que lo superan, una parcela, un patio; el hombre está apenas plantado, es un hombre-árbol, "y vemos un árbol, sólo un árbol en la playa insaciable", siguiendo las implicaciones de este epígrafe tomado de Héctor Rojas Herazo.

El cronotopo del patio se encuentra entonces inscrito en la temática reflexivo-existencial del texto, como se aprecia en el poema "Concorde", con sus implicaciones nocturnas, en tanto umbral y paraíso. El hombre es entonces un niño (Cfr. Torres Duque, 1992: 54). en su incurable soledad, asediado, por sus eternos enigmas, el misterio de la existencia, las razones de la precariedad (la mancha) de la misma, su destino final:

En esa hora del año

un hombre escocido de luz y cansancio

ha de coger un balde, cruzar el patio,

llegar al pozo y mandar

el cubo a las sombras (...)

Y aquél hombre, ya viejo,

suavizado por lo años como un borde,

ha de coger un tazón de peltre

y ofrecerlo, rebosante, a un niño.

Ninguno de nosotros,

ni el más sabio, ni el más humilde,

ni el más amante,

podrá decir en aquél instante

si el sediento bebió

un líquido con sabor a firmamentoo

o si una sombra que subió del Hades profundo 
vino

a

manchar

para

siempre

$\mathrm{su}$

garganta.

En cada verso se es consciente de la precaria condición del ser humano, de que la muerte acecha marcando los límites del patio, de la vida: "Para morir bastas tú/ negra cosecha del tiempo", sin importar cuán alto en "este bosque" llegue la mano hombre (Jursich, 1990: 17). Por eso el hablante, consciente de la ineludibilidad de la muerte, a pesar de lo esplendorosa que puede llegar a ser la vida, hace de cada poema la contemplación casi estoica de ese Destino Fatal. De ahí que, junto al árbol, el símbolo más recurrente en Glimpses sea la fruta, la cual, en su morbidez, lleva inscrito ese destino: podrirse. Y ante la irreversible ruina del no-Eterno "llameante vivir" se contempla, en el retorno a la tierra, la integración en el ritmo cíclico del universo:

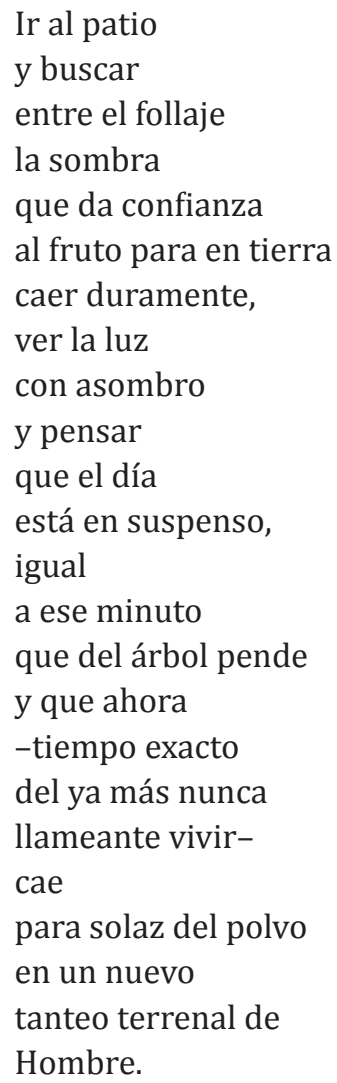


Por todo lo expuesto -y es esta la conclusión del presente ensayo- en cuanto elemento integrante de un imaginario cultural compartido, cuya inicial elaboración literaria es susceptible de ser ubicada en un pasado histórico, por lo menos en lo concerniente a la historia literaria regional ${ }^{15}$, es que podemos afirmar que, a partir de la recurrencia de la imagen cronotópica del patio, existe una verdadera tradición literaria regional en el Caribe colombiano.

\section{Observaciones finales}

Somos conscientes de que a partir de una perspectiva regionalista podría parecer, para algunos, el sostenimiento de una consideración substancialista a la hora de tratar el complejísimo tema de las identidades culturales; posición que carecería de vigencia en un mundo globalizado donde las nociones de territorio podrían carecer de importancia a la hora de definir posibles identidades locales. Sin embargo, creemos que si algo se constata en el presente ensayo es el hecho de que la definición de cualquier identidad, individual o cultural -específicamente cultural en nuestro caso- ${ }^{16}$, es ante todo una construcción que obedece a proyectos de diferenciación y de legitimación de posibles o reales particularidades tanto geográficas como culturales.

Este es el caso, como ya vimos, del proyecto de una literatura latinoamericana en el que se inscribió la producción de la primera obra de Rojas Herazo, y que explica también el carácter legitimador que los escritores posteriores le adjudican a dicha obra. Todo esto remite a uno de los temas más recurrentes a la hora de tratar la literatura latinoamericana: la urgencia de consolidar una memoria como prerrequisito de la conformación de una identidad cultural. Reconocer el carácter construido de las identidades culturales y sus relaciones con las nociones de territorio y región implica necesariamente no renunciar al derecho que tiene cada comunidad de definir su propia manera de ver y estar en le mundo en pro de un proceso globalizador que, aunque irreversible no puede -ni debe- propenderse como absoluto. Hemos visto aquí cómo el acceso a la universalidad de la literatura del Caribe colombiano se basa en el reconocimiento y la valoración de las particularidades culturales propias que han efectuado sus escritores.

\footnotetext{
${ }^{15}$ Esta concepción de la tradición como herencia cultural la hemos tomado de Rama (1984: 205).

${ }^{16}$ Incluyendo la identificación globalizante que tiene más bien a la uniformidad minimizando y hasta folklorizando las diferencias.
} 
No se trata de negar la evidente realidad de que la literatura del Caribe colombiano hay que verla en el entramado de la literatura nacional o universal, pues se sabe que nadie es sino en relación con un otro, y una afirmación tal caería por su propio peso. Pero sucede que en el fondo este ensayo ha sido también un intento de definir una actitud propia ante uno de los interrogantes de este fin de siglo, donde cada cultura sobrevivirá en la medida en que pueda, desde una firme, pero flexible posición propia, negociar con las tendencias globalizantes. Se trata, en suma, y siguiendo a García Canclini (1992), de la búsqueda de un enfoque que permita saber "cómo ser radicales sin ser fundamentalistas" (348).

\section{Bibliografía}

Arango, Gustavo. (1995). Un ramo de no me olvides, Gabriel García Márquez. Cartagena: El Universal.

Bajtin, Mijail. (1989). Teoría y estética de la novela. Madrid: Taurus.

Bachelard, Gastón. (1965). La poética del espacio. México: F. C. E.

Brushwood, J. Stub. (1989). La novela hispanoamericana del siglo XX, una vista panorámica. México: F. C. E. . (1994). "En diciembre llegó Celia: Tres novelas de Héctor Rojas Herazo". En: García Usta, Jorge. (comp.). Visitas al patio de Celia. Cartagena: Alcaldía de Cartagena.

Burgos Cantor, Roberto. (1995). Pavana del ángel. Bogotá: Planeta. - (1985). El oscuro sello de Dios. Cartagena: Lotería de Bolívar. . (1990). Lunación del amor. Cartagena: Ediciones En Tono Menor.

Bustos Aguirre, Rómulo (1995). En el traspatio del cielo. Bogotá: Colcultura. Cárdenas Páez, Alfonso (junio de 1993). "El universo sincrético en Celia se pudre", Historia y cultura, Universidad de Cartagena, Año 1, No. 1, págs. 83 ss.

Durand, Gilbert. (1981). Las estructuras antropológicas de lo imaginario. Madrid: Taurus.

Eliade, Mircea (1992). Lo sagrado y lo profano. Barcelona: Labor (9a ed.).

Figueroa A., Cristo R. (1995). "El vuelo de la paloma en el universo narrativo de Roberto Burgos Cantor". En: Giraldo, Luz Mary (comp.), Fin de siglo: Narrativa colombiana. Cali: Ceja.

García Canclini, Néstor. (1992). Culturas híbridas. Estrategias para entrar y salir de la modernidad. México: Grijalbo.

García Usta, Jorge. (1995). Cómo aprendió a escribir García Márquez. Medellín: Lealon, . (1990). "Confesiones de un patiero", Boletín cultural y bibliográfico, Banco de la República, No. 24 / 25. - (agosto 16 de 1992). "García Márquez y Rojas Herazo, las raíces de la magia común", Magazín Dominical, de El Espectador. 
Giraldo Luz Mery. (1982). "El encantado y su amaga desdicha”, Gaceta Colcultura, No. 37/38 (V), págs. 14-16.

Gómez, Blanca Inés. (1995). "Héctor Rojas Herazo: espacio y memoria”. En Fin de siglo: Narrativa colombiana. Cali: CEJA, págs 45-59.

Heller H., Ben. (1994). "Lectura marginal de un texto marginado”. En García Usta, Jorge. (comp.). Visitas al patio de Celia. Cartagena: Alcaldía de Cartagena.

Jaulin Robert. (1987). Juegos y juguetes. Ensayos de etnotecnología. Barcelona: Siglo XXI.

Jursich Durán, Mario. (1990). Glimpses. Bogotá: Fundación Simón y Lola Guberek, Vol. 36.

Lotman, Yuri. (1970). La estructura del texto artístico. Madrid: Istmo.

Mogollón, Elsa. (20 de marzo de 1988). "Héctor Rojas Herazo: un revolucionario de la literatura", Revista Dominical de El Heraldo, Barranquilla.

Nieves Oviedo, Jorge. (diciembre de 1994). "En el traspatio del mitos”. En: Historia y Cultura, Universidad de Cartagena, Año II, No. 3, págs. 211-214.

Noriega, Teobaldo. (1989). "Polifonía neobarroca en El patio de los vientos perdidos de Roberto. Burgos Cantor”. En Pineda Botero, Álvaro y Williams L., Raymond. De ficciones y realidades. Perspectivas sobre literatura e historia colombiana. Bogotá: Tercer Mundo Editores y Universidad de Cartagena, págs. 169 ss.

Olaciregui, Julio. (junio 9 de 1996). "Roberto Burgos Cantor: el hombre que escribe historias para alejar el miedo". Dominical de El Universal, Cartagena, No. 537, pp. 5-7.

Pineda Botero, Álvaro. (1990). Del mito a la postmodernidad, la novela colombiana de finales de siglo XX. Bogotá: Tercer Mundo.

Pineda Botero, Álvaro y Williams L., Raymond. (1989). De ficciones y realidades. Perspectivas sobre literatura e historia colombiana. Bogotá: Tercer Mundo Editores y Universidad de Cartagena.

Rama, Ángel. (1984). La novela latinoamericana 1920-1982. Bogotá: Procultura. . (1991). Gabriel García Márquez o la edificación de un arte popular y nacional. Bogotá: Colcultura.

Restrepo J., Guillermo \& García Detjen Lácides. (22 de septiembre de 1979). "Reportaje a Héctor Rojas Herazo”, Suplemento Libertad, Barranquilla.

Rojas Herazo, Héctor. (1962). Respirando el verano. Bogotá: Planeta. . (1976). "A cada hombre le pasa el tiempo", Revista Cuadernos Hispanoamericanos, Bogotá. . (1976). Señales y garabatos del habitante. Bogotá: Colcultura. . (1982). Celia se pudre. Madrid: Alfaguara. (noviembre 27 de 1994). Magazín Dominical de El Espectador, No. 604 (número monográfico), Bogotá.

Siemens L., Williams (1989). "El efecto mariposa en el patio de los vientos perdidos”. En: Pineda Botero, Álvaro \& Williams L., Raymond. De 
ficciones y realidades. Perspectivas sobre literatura e historia colombiana. Bogotá: Tercer Mundo Editores y Universidad de Cartagena, págs. 161 ss.

Shaw L., Donald. (1988). Nueva narrativa hispanoamericana. Barcelona: Crítica.

Segre, Cesare. (1985). Principios de análisis del texto literario. Barcelona: Cátedra.

Torres Duque, Oscar. (1992). La poesía como idilio: la poesía clásica en Colombia. Bogotá: Colcultura.

Troncoso, Marino. (1998). "Núcleo Imaginario de una visión del mundo. Aproximaciones a la obra de Héctor Rojas Herazo". En De ficciones y realidades. Perspectivas sobre literatura e historia colombiana. Universidad de Cartagena y Tercer Mundo.

Urrea Restrepo, Adriana. (junio 9 de 1996). "Trazos de un universo", Dominical de El Universal, Cartagena, No. 537, págs. 10-11.

Verón, Elíseo. (1989). La semiosis social. México: Gedisa.

Villegas, Juan. (1984). Teoría de historia literaria y poesía lírica. Canadá: Giral Books Inc.

Williams, Raymond. (1981). Una década de la novela colombiana. La experiencia de los setenta. Bogotá: Plaza y Janés. 